\title{
Challenges that Preventive Conservation poses to the Cultural Heritage documentation field.
}

\author{
K. Van Balen \\ KU Leuven, Civil Engineering Department \& Raymond Lemaire International Centre for Conservation \\ Kasteelpark Arenberg 40, 3001 Heverlee, Belgium \\ koenraad.vanbalen@kuleuven.be
}

\section{Commission II, WG II/8}

KEY WORDS: preventive conservation, principles, integrated approach, documentation requirements, documentation challenges, heritage value, damaging mechanism.

\begin{abstract}
:
This contribution examines the challenges posed to the cultural heritage documentation community (the CIPA community and others) in implementing a preventive conservation approach of the built heritage in today's society.

The "DNA" of Preventive Conservation.

Various authors so far support the argument that preventive conservation is an effective way to respond to the challenges society faces with the preservation of its Cultural Heritage (Van Balen, 2013).

A few decades of experiences with the application of preventive conservation in the field of immovable heritage in the form of Monumentenwacht in The Netherland and in Flanders have shown that a good monitoring of the state of preservation with a strong push for maintenance activities contributes to more preservation of authenticity, to more cost-effective preservation and to empowering society in dealing with heritage preservation. (Cebron, 2008)

An analysis of these and similar experiences demonstrates that these "Monumentenwacht" activities represent only a part of what could be named a preventive conservation system. Other fields in which prevention is advocated for its higher efficiency, show the importance of system thinking in the development of improved strategies.

Applying this approach to the field of the immovable heritage, referring to the initial results shown by the Monumentenwacht practices, it becomes clear that different dimension are at stake simultaneously: the preservation of authenticity or integrity, the management of resources and the connection with society. It shows that the analysis of challenges in heritage preservation and the development of strategies is à priori multifaceted and therefor has a certain level of complexity.

The sustainability of the preservation of cultural heritage buildings and sites can be measured according to its multiple economic, social, environmental and cultural support. The Cultural Heritage Counts for Europe report shows that the more diverse the support is for cultural heritage preservation actions, the more those actions will contribute to sustainable development and the more sustainable the preservation of that heritage will be. This reasoning has led to the "upstream approach" which argues that cultural heritage preservation can benefit from a variety of resources which do not necessarily have to be earmarked for it à priori (CHCfE, 2015).

It leads to arguing for an holistic and integrated approach for cultural heritage preservation that taps into different kinds of resources, which requires acknowledgement of the complex nature of understanding and managing heritage values into an overall societal development goal (Vandesande, 2017).
\end{abstract}

Challenges in the Cultural Heritage documentation field.

Documentation needs in the field of cultural heritage preservation therefor are challenged by the complexity of the sources of information, by the need to integrate them in an holistic tool and by the way they are able to dialogue with society.

1. The proper analysis of heritage requires increasing efforts by the diversity of sources and the complexity of their interaction. This (complexity acknowledging) analysis should be linked to monitoring tools which eventually contribute to monitor cultural heritage values. This monitoring is also a documentation challenge as it has to be pertinent and dynamic. Analysis and monitoring are important as they are the basis for understand threats that impact heritage values.

2. As resources for heritage development or heritage guided development can have a variety of origins, their documentation and analysis -compared to the traditional curative object oriented preservation- should be extended to include many more possible resources. Experiences exist with documentation of the physical environment of heritage sites but the upstream approach points toward a larger number of development resources that can be tapped into. This implies the need to identify new approaches, to document them and to integrate them in a dynamic analytical process.

3. As preventive conservation focusses not only on the empowerment of the owners and managers but also on a better integration of a wider group of stakeholders, the question of ownership and continuous co-creation challenges the documentation process as well.

4. Longevity of documentation: the need for continuous updating and monitoring as part of the cyclic approach of PC challenges the longevity, accessibility of the documentation itself and the tools that will use them in the future. 


\section{INTRODUCTION}

\subsection{Today's challenges in the heritage conservation field}

Together with overall society's changes, the way heritage is perceived and valued evolves as well.

The Nara document on authenticity (Nara, 1994) enlarged the heritage authenticity concept to respond at the international level to the aspirations of various cultures. Consequently it also allowed each of those culture to integrate more diverse aspects of heritage into their way of valuing it (Van Balen, 2008). It helped -mostly in our Western societies- to appreciate heritage values beyond the physical elements only. While in the guiding documents in the middle of the $\mathrm{XX}^{\circ} \mathrm{C}$, as the Venice charter, started from the physical objects as a starting point of concern, today's approach is increasingly centred around heritage values. Such changes of perspectives and valuing therefor implies other ways of communication thus other ways to document the multiple layered heritage values. In his dissertation on the use of three-dimensional techniques of documentation and dissemination in studying built heritage, Mario Santana started with identifying the link between documentation and authenticity (Santana, 2003).

Studies that aim at protecting, promoting, or conserving a monument are based on the identification and evaluation of the heritage values inherent to it, i.e. understanding the authenticity of it and considering it as a layered concept of values (Van Balen, 2003).

Documentation of this information is therefore important, and Santana's study demonstrated that the Nara Grid could be used as a "container" of that information. The result is that the actual authenticity value can be documented considering the different layers, based on the state of the fabric, and that simulations could be done considering modifications that could affect the aging process and the natural development of the object in its setting. (Van Balen, 2008)

\subsection{Preventive conservation}

The preservation of heritage and its acknowledged values aims at its safeguarding and its transfer in a sustainable way to next generations. This requires a multifaceted approach, tapping into different strategies and tools that contribute to that goal. These can be "curative" or "preventive", as argued in previous publications, using the analogy with medicine, they can be compared with "Curative (medical) Care" versus "Public Health" (Van Balen, 2015).

The object oriented heritage preservation strategies practiced in the past as expressed in the Venice Charter was very much oriented towards a curative conservation practice.

The attention for prevention and maintenance in the field of conservation of monuments and sites is not recent although it is gaining attention. The Charter of Athens (1931), article 4 of the Venice Charter (1964), the recommendations from the Council of Europe (Council of Europe, 1981) on Maintenance, preventive actions and crafts (1980s) but also the Burra charter refer to the role of maintenance for heritage and society (Cebron, 2008). A few common denominators can be found in the arguments given in these documents: preventive conservation helps conserving authenticity as it avoids or minimize the increase of damage thanks to early maintenance and -if necessary- some interventions. From this it is usually deduced that preventive conservation is cost effective. The use of buildings and the proper integration in society enhance the chances for good maintenance. Experiences with monumentenwacht in The Netherlands and in Flanders support the arguments that a preventive conservation approach empowers society at large to take care of its heritage by maintaining it. It is also found that it widens the responsibility for preservation to a larger fraction of society than traditional conservation practices do (Van Balen, 2015).

A state of the art of the understanding and implementation of preventive conservation of the built heritage has been shared in previously (Van Balen 2013).

\subsection{Changing needs, changing documentation tools}

The Cultural Heritage Counts for Europe report (CHCfE, 2015) stresses the need for an integrated approach in which the social, cultural, environmental and economic impacts of heritage are fundamentally intertwined. It states that past and current assessment of cultural heritage investments based on the (so-called) downstream do not show the full potential of cultural heritage. In a truly integrated approach towards heritage, the benefits of heritage can be maximised. The report (CHCfE, 2015) proposes an upstream approach to cultural heritage, whereby traditional economic investment schemes are enhanced with resources from other sectors. This implies introducing non-heritage investment of resources to achieve in parallel non-heritage goals (e.g. social cohesion or reducing unemployment) as well as the safeguarding of cultural heritage assets. Taking full potential of the upstream approach, combined with a closer integration of heritage's social, economic, cultural and environmental impacts implies that cultural heritage becomes a source for sustainable development. The report (CHCfE, 2015) also shows that the more the output is diversified over different pillars of sustainable development, the more sustainable the resulting development will be.

Another important challenge debated recently e.g. in the margin of the last World Heritage Committee also demonstrates that heritage communities are facing ever evolving challenges from novel threats. It deals with defining how to respond to the deliberate destruction of (World) Heritage. This debate reveals the need for a better understanding of the role of heritage for society's past traumatic development and a preventive attitude to these (new?) types of reality.

\subsection{Structure}

The following chapters will further develop the documentation challenges that preventive conservation entails in today's perspective of heritage preservation after recalling some of the essential features of the Preventive Conservation approach.

\section{THE "DNA" OF PREVENTIVE CONSERVATION}

\subsection{Preventive conservation addresses damaging causes.}

The concept of "preventive conservation" is in strong contrast with the traditional approach of "curative" conservation. Wellmaintained and monitored Cultural Heritage is better prepared to respond to the wide variety of challenges it faces. 
Built Cultural Heritage conservation approaches still mainly focus on curative conservation and restorative treatments. Curative conservation activities often do not result in the removal of causative factors. Once conserved, the object frequently returns to an environment leading to further deterioration, likely requiring future interventions, and establishing a reactive pattern of treatment (Dann, 2004). Preventive Conservation approach differentiates itself from curative conservation as it addresses deterioration causes, emphasises maintenance works and presumes a systematic condition assessment by means of monitoring. Thereby the main benefits of a Preventive Conservation approach for built heritage are the cost-effectiveness for private owners and managers of built heritage (Forster, 2009), the quality protection of built heritage and environmental enhancement, prolongation of the physical service life of buildings and building parts (Van Balen, 2013), the empowerment of local communities in dealing with heritage and the exploitation of their services in Cultural Heritage Services (Della Torre, 2010).

\subsection{Risk management}

Risk management is the process of identifying, assessing and analysing expected and possible damage to heritage sites and of developing mitigation strategies in order to reduce the risk of damage (Paolini, 2012). Decision-makers in many fields use this approach in order to reduce losses. In the case of Cultural Heritage this approach helps also to reduce loss of authenticity. The adoption and application of an appropriate risk management approach by organizations involved in the management of Cultural Heritage sites requires tools to assist them in their conservation and management planning decisions. The Sendai international policy for disaster risk reduction includes many references to culture and heritage (UNISDR 2015). In order to reduce disaster risks, it stresses two aspects: 1) sharing of information and how they information is collected; and 2) investments in the economic, social, health, cultural and educational resilience of persons, communities and countries. The latter in fact deals with "empowering", which is dealt with in the next paragraph.

In the report "Risk Management at Heritage Sites: a case study of the Petra World Heritage Site." (Paolini, 2012), disturbances and threats on heritage sites have been identified, as detectable impacts. They have been linked to a slightly modified set of ten agents of deteriorations used by Monumentenwacht Flanders and based on (Waller, 1995), in order to identify what caused those disturbances or threats. Agents of deteriorations are mechanisms and processes that separately or jointly cause damage or threaten heritage. Once a threat, as consequence of an agent, is identified and its probability and severity have been assessed, its magnitude of risk can be defined. The identification and recording of those agents of deterioration on the other hand, will help to identify methods of mitigation and treatment (Paolini, 2012). Therefor the proper documentation of those agents and their effect in an information depository is critical for a proper risk estimation and monitoring.

\subsection{Empowering}

Preventive Conservation broadens the responsibility for preservation to a larger fraction of society than traditional conservation practices do (Van Balen, 2015).

In order to reduce disaster risks the "Sendai Framework for Disaster Risk Reduction" (UNISDR 2015) also stresses the importance of investments in the economic, social, health, cultural and educational resilience of persons, communities and countries.

Its proper implementation empowers local communities in dealing with heritage (Della Torre, 2010) and the exploitation of their services in Cultural Heritage Services.

\subsection{Monitoring}

In the article "A Value-Based Monitoring System to Support Heritage Conservation Planning" Heras and co-authors has proposed a combined heritage values and risk assessment based approach (Heras, 2013).

It is based on the "Preventive Conservation Cycle" methodological model derived from the ICOMOS Charter Principles for the Analysis, Conservation and Structural Restoration of Architectural Heritage - (ICOMOS, 2003). The peculiarity of this model is its association with public health principles which acknowledge the importance of monitoring. It is a never ending continuous loop of updating information that helps to understand and helps to intervene when required. The never-ending loop identifies four steps: analysis, diagnosis, therapy and control, corresponding, respectively, to the search for significant data and information, individualization of the causes of damage and decay, choice of the remedial measures and control of efficient interventions (Van Balen, 2013).

From this outline, it becomes clear that each of the four steps in the preventive conservation approach will use, produce and output new information. To comply with this approach, the proposed monitoring system requires the availability of accurate information on the different types of transitory values present at different scales and levels of detail, and the availability of different studies which provide indicators of degradation (disturbances), potential damages, treats and agents of deterioration affecting the identified values (Heras, 2013).

\subsection{Preventive Conservation documentation requirements}

The previous paragraphs have identified specific aspects that documentation and information in a preventive conservation approach require. Not only are the types of information specific, their updatability as part of a monitoring tool is an essential requirement.

As stated in article 3.22 of (ICOMOS, 2003): all the activities of checking and monitoring should be documented and kept as part of the history of the structure.

Considering the broader social basis, there is a need for sharing them with the community for management and for empowering. This needs also puts requirements on the type of documentation and the type of depositories. 


\section{CHALLENGES IN THE CULTURAL HERITAGE DOCUMENTATION FIELD.}

Based on the specific needs for preventive conservation and previously mentioned societal changes in which valuing and managing cultural heritage is occurring a number of challenges can be addressed that the heritage documentation community has to address.

\subsection{Monitoring heritage values and state of preservation.}

The Nara grid presented earlier, can be a container to systematize the information of the layered concept of heritage values. It can capture a variety of sources of heritage values for immovable cultural heritage sites. It can be used to monitor changes over time and to develop collect relevant information at different scales. But as mentioned during the review process of the related article (Van Balen, 2008) in the thematic APT journal issue, the use of the Nara grid does not allow to measure, sum up or benchmark heritage values of a site. It therefor can't assess in an unambiguous way (e.g. a figure) which strategy would realize more heritage values than another. It could however allow to generate a base line that can serve for monitoring or estimation of strategies. Such estimations require multi-disciplinary teams. Experience so far has demonstrated that the major benefit is that the Nara Grid has been and can be used as a mental scheme to investigate and report on aspects and dimensions of authenticity of the built heritage. It is therefore used as a transparent interdisciplinary communication tool. As it is not meant as a quantitative methodology that would allow "measuring" the level of authenticity, it is best used rather as a checklist and to understand the limits of its use.

Preventive conservation approaches point to the need for monitoring, the identification and monitoring of mechanisms that affect heritage values. Monitoring is based on the concept of time and changes. It requires the possibility to update information while keeping track of the history of previous recordings and documentation as a source for identification of changes. Monumentenwacht Flanders (Monumentenwacht) and similar organisations have developed documentation methods that allow to report on the state of preservation of heritage buildings and sites in a systematic way.

After approximately twenty years Monumentenwacht Flanders has improved their documentation system, not only to allow a better integration of data from the different provinces but also to align the documentation with risk assessment and with a service that it delivers to its members, the "Meerjaren Onderhouds Plan (MOP)" or multi-year maintenance plan. The "MOP" plan is based on the (last) condition report and gives an estimate of the expected costs related to maintenance year by year for the next 6 years. (Vandesande 2017). The cost estimation is based on understanding the impact of risks that affect heritage values. It uses information on the plausible impact of agents of deterioration and is based on a condition report. This demonstrates the need for interconnection of information, for a correct and smart structuring of information and a reliable and regular monitoring. Let's also consider that as insights will evolve, information sources will evolve as well, therefore the smart integration of information will have to be flexible while assuring that historic monitoring evidences remain useful.
There are many challenges laying ahead of us how new technologies may help to collect in a more effective way the information needed for condition reporting but also how the data can be interconnected to improve a preventive conservation based management of cultural heritage.

\subsection{Resources for heritage development or heritage guided development}

The Cultural Heritage Counts for Europe report (CHCfE, 2015) as well as a multitude of European directives acknowledge the potential contribution of cultural heritage to sustainable development. The upstream approach (CHCfE, 2015) identified the potential of introducing non-heritage funding (attribution of resources, not only in monetary terms) to achieve in parallel non-heritage goals (e.g. social cohesion or reducing unemployment) as well as to safeguard cultural heritage assets. Taking full potential of the upstream approach, combined with a closer integration of heritage's social, economic, cultural and environmental impacts, then also means that cultural heritage becomes a source for sustainable development. The challenges the heritage community will face is to identify and document those other resource streams and to develop methods to estimate their contribution to safeguarding cultural heritage. This more integrated and holistic approach of cultural heritage is very much in line with the preventive conservation approach.

Today we may ask ourselves in which way will new (digital) technologies or development strategies (integrated spatial planning,....) help to integrate cultural heritage as an asset or even involve cultural heritage in its own stream of resources?

\subsection{Continuous co-creation challenges}

The above mentioned integrated and holistic approach, the preventive conservation approach and the shift from an expert centred valuing of heritage to a more community centred valuing leads to a the need for novel communication tools and instruments for negotiation and co-creation in collaboration with all involved stakeholders.

The Sendai international policy for disaster risk reduction (UNISDR 2015) stresses the importance of sharing of information and how they information is collected to integrate the viewpoints of those different stakeholders. Digital workflows can be of great benefit to facilitate the preservation of cultural heritage by facilitating exchange, sharing and cocreation of information, considering the access to that information is fair, reliable and impartial.

\subsection{Longevity of documentation}

Finally, considering the importance of monitoring in the preventive conservation approach a next challenge in the digital world may be related to the long term access of (digital) information by an expanding crowd of stakeholders. Longevity and accessibility of information may become crucial requirements to facilitate monitoring and so for preventive conservation.

\section{CONCLUSIONS.}

Digital workflows can be of great benefit to facilitate the preservation of cultural heritage. It can facilitate exchange, 
sharing and co-creation of information for heritage conservation. The evolving nature of what society considers cultural heritage, the layered concept of heritage values and the changing nature of the resources available for the management of cultural heritage generate new requirements to the (professional) heritage documentation society. Positioning cultural heritage as central in (spatial) planning policy as "health" is central to public health policy requires is the essence of a preventive conservation strategy. Key to such a preventive conservation strategy are monitoring, empowering stakeholders to support the broadening of the preservation basis and appropriate risk management that put heritage values at the core. Technological development can improve those key-factors but at first glance it becomes evident that the major breakthroughs will have to come from strategies, smart integration and devoted stakeholders who believe in the sustainable development power of cultural heritage. A list of challenges and resulted requirements have been identified that aim at helping the cultural heritage documentation community (the CIPA community and others) in implementing a preventive conservation approach of the built heritage in today's society.

\section{ACKNOWLEDGEMENTS}

The holder of the PRECOM ${ }^{3}$ OS UNESCO chair on Preventive Conservation, Monitoring and Maintenance of Monuments and Sites acknowledges the long standing support from the Janssen Pharmaceutica Fund on Preventive Conservation established at KU Leuven and the various researchers involved in the research activities of the chair in various countries.

\section{REFERENCES}

Cebron Lipovec, N., Van Balen, K., 2008. Practices of monitoring and maintenance of architectural heritage in europe: examples of "monumentenwacht" type of initiatives and their organisational contexts. In Kolar, J. (Ed.), CHRESP: Cultural Heritage Research Meets Practice. CRESP. Lubljana, 10-12/11/2008. Ljubljana: CIP. pp. 238-239.

Cultural Heritage Counts for Europe, 2015. CHCfE Consortium. 2015. Retrieved from: http://bit.ly/2jERIwx. $(02 / 07 / 2017)$

Dann, N., Wood, S., 2004. Tensions and omissions in maintenance management advice for historic buildings, Structural Survey, 2(3). pp. 138- 147.

(Della Torre, 2010). Della Torre, S. 2010. "Preventiva, Integrata, Programmata: le Logiche Coevolutive della Conservazione". In: Biscontin, G., Driussi, G. (Eds.), Pensare La Prevenzione: Manufatti, Usi, Ambienti, Atti del Convegno, Venice : Edizioni Arcadia Ricerche). pp. 67-76.

Forster, A. and Kayan, B., 2009. Maintenance for Historic Buildings: A Current Perspective. Structural Survey, 27(3), pp. 210-229.

Heras Barros V., Wijffels A., Cardoso F., Vandesande A., Santana Quintero M., Van Orshoven J., Steenberghen T., Van Balen K., 2013. A Value-Based Monitoring System to Support Heritage Conservation Planning., Journal of Cultural Heritage Management and Sustainable Development, 3 (2), pp. 130-147.
ICOMOS Principles for the Analysis, Conservation and Structural Restoration of Architectural Heritage, 2003. Retrieved: https://iscarsah.files.wordpress.com/2014/11/iscarsahprinciples-english.pdf $(02 / 07 / 2017)$

Monumentenwacht Vlaanderen http://www.monumentenwacht.be/sites/www.monumentenwac ht.be/files/page/BrochureEnglish.pdf (02/07/2017)

Nara document on authenticity, 1994, retrieved from: www.icomos.org/charters/nara-e.pdf

Paolini A., Vafadari A., Cesaro G., Santana Quintero M., Van Balen K., Vileikis O., Fakhoury L., 2012. Risk Management at Heritage Sites: a case study of the Petra World Heritage Site. Paris: UNESCO and KU Leuven, 168 p. (available on UNESCO website).

Santana Quintero M., 2003. The Use of Three- Dimensional Techniques of Documentation and Dissemination in Studying Built Heritage, unpublished $\mathrm{PhD}$ dissertation, Raymond Lemaire International Center for Conservation, KU Leuven.

UNISDR: United Nations Office for Disaster Risk Reduction (UNISDR), 2015. Sendai Framework for Disaster Risk Reduction 2015-2030: (A/CONF.224/CRP.1). Retrieved: www.unisdr.org/files/43291_sendaiframeworkfordrren.pdf $(02 / 07 / 2017)$

Van Balen, K., 2003, From Conservation Principles to Materialization (Or the Other Way Around: How Is Materialization Guided by Principles?)," in Van Gemert, D. (Ed), Consolidation of Masonry: Advances in Materials Science and Restoration, vol. 1, Aedification Publishers, Freiburg, pp. 135-144.

Van Balen K. 2008. The Nara Grid: An Evaluation Scheme Based on the Nara Document on Authenticity. APT bulletin, 49 (2-3), pp. 39-45.

Van Balen K., Vandesande A., 2013. Reflections on Preventive Conservation, Maintenance and Monitoring of Monuments and Sites, PRECOMOS UNESCO-chair, Acco, Leuven.

Van Balen K., 2015.Preventive Conservation of Historic Buildings. International Journal for Restoration of Buildings and Monuments, 21 (2-3), 99-104.

Vandesande, A. 2017. Preventive Conservation Strategy for Built Heritage Aimed at Sustainable Management and Local Development., unpublished PhD; KU Leuven.

Venice Charter: International Charter for the Conservation and Restoration of Monuments and Sites; The Venice Charter, 1964. retrieved from: www.icomos.org/charters/venice_e.pdf $(02 / 07 / 2017)$

Waller, R., 1995. Risk management applied to preventive conservation. In: Rose, C.L., Hawks, C.A. and Genoways, H.H. (eds.). Storage of Natural History Collections: A Preventive Conservation Approach, pp. 21-28. 